\title{
Knee osteoarthritis in professional football is related to severe knee injury and knee surgery
}

Vincent Gouttebarge ${ }^{1,2,3,45^{*}} \mathbb{D}$, Haruhito Aoki, ${ }^{6,7}$ and Gino M. M. J. Kerkhoffs $2,3,4,5$

\begin{abstract}
Background: As a consequence of severe knee injuries, knee osteoarthritis $(O A)$ seems prevalent in retired professional footballers. However, some epidemiological data remain missing, for instance whether knee OA is also prevalent in current professional footballers, whether knee $O A$ is associated with knee injuries and surgeries, and whether knee OA leads to a lower level of functioning. Therefore, three research questions were answered: (i) what is the prevalence of knee osteoarthritis $(\mathrm{OA})$ among current and retired professional footballers? (ii) is severe knee injury or knee surgery associated with knee OA among current and retired professional footballers? (iii) what are the consequences of knee OA on physical knee function among current and retired professional footballers?

Methods: An observational study based on a cross-sectional design by means of questionnaires was conducted. Participants were current and retired professional footballers recruited by the World Players' Union (FIFPro). Information about severe knee injury and knee OA was gathered (medical record or team doctor), while physical knee function was assessed through a validated scale.
\end{abstract}

Results: A total of 1360 participants (964 current and 396 retired professional footballers) were enrolled in the study (response rate of 54\%). Prevalence of knee OA was 13\% among current players and 28\% among retired players $(p<0.01$ ), being higher among older players. Current and retired professional footballers were nearly twice as likely to suffer from knee OA by every additional severe knee injury and by every additional knee surgery (risk ratio: 1.72-1.96; $p<0.01$ ). Current and retired professional footballers with knee OA reported a lower level of physical knee function than current and retired players without $\mathrm{OA}(p<0.01)$, their physical knee function being also lower than reference values (adult population, young athletic population and amateur footballers).

Conclusion: The prevalence of knee OA was higher among retired than among current professional footballers and reached up to $40 \%$, leading to negative consequences for their physical knee function. Current and retired professional footballers were nearly twice as likely to suffer from knee OA by every additional severe knee injury and by every additional knee surgery incurred during their career. Management of knee OA should be prioritized among professional footballers, especially to prevent the worsening of the condition during their retirement years.

Keywords: Knee osteoarthritis, Professional football, KOOS, Knee injury, Knee surgery, Physical function

\footnotetext{
* Correspondence: v.gouttebarge@fifpro.org

'World Players' Union (FIFPro), Scorpius 161, 2132 LR Hoofddorp, The

Netherlands

${ }^{2}$ Department of Orthopaedic Surgery, Academic Medical Center, University of

Amsterdam, Amsterdam Movement Sciences, Amsterdam, The Netherlands

Full list of author information is available at the end of the article
} 


\section{Background}

Worldwide, osteoarthritis (OA) is the most common rheumatic disease and is expected to become the world's fourth leading cause of disability in 2020 (Felson 2004; Hunter et al. 2008). As a consequence of symptoms and activity limitations, OA leads to medical costs and costs due to productivity loss of near $€ 900$ per patient per month, twice as much as other chronic diseases such as diabetes (Hermans et al. 2012). Risk factors for developing $\mathrm{OA}$ are well known and include age, gender, obesity, (traumatic) injury, surgery, cumulative exposure to ball sport games, athletics or gymnastics, and abnormal biochemical loads on the joints during occupational activities (Hunter et al. 2008; Lohmander et al. 2007; McWilliams et al. 2011; Vrezas 2010). In current or retired professional athletes, OA results from a complex interaction of biological, mechanical, and biochemical factors, and is further precipitated by traumatic or overuse injuries which accelerates intra-articular pathological processes (Bennell et al. 2012; Kirkendall and Garrett 2012). As a result, current or retired athletes have an earlier onset and higher prevalence of OA than would be expected based on their age, especially those with a history of joint injury (Bennell et al. 2012; Kirkendall and Garrett 2012).

In professional football, the overall risk of injury was estimated to be 1000 times higher when compared to typical high-risk industrial occupations like in manufacturing, construction or in the service sector (Drawer and Fuller 2002). During their career, professional footballers are at risk of suffering from severe injuries, especially in their knees. In the UEFA Elite Club Injury Study during the seasons 2001-2015, an overall ACL injury rate of 0.066 per $1000 \mathrm{~h}$ was found, the match ACL injury rate being 20 times higher than the training injury rate (Walden et al. 2016). Another 5-year prospective cohort study among Australian professional footballers showed that a typical squad with 25 players can expect between 4 and 8 severe knee injuries (time-loss including at least one official match) every season (Gouttebarge et al. 2016a). With regard to the risk factors for OA and the rate of knee injuries in professional football, it is not surprising that retired professional footballers show prevalence rates of knee OA ranging from $40 \%$ to $80 \%$, which is higher than in the general population (Fernandes et al. 2017; Kuijt et al. 2012; Lohkamp et al. 2017; Schuring et al. 2016). Furthermore, knee OA seems to impair functioning of retired professional footballers but the body of scientific evidence remains limited (Gouttebarge et al. 2014).

Despite this available scientific evidence, an empirical study exploring the prevalence of knee OA among both current and retired professional footballers is still lacking. Furthermore, some epidemiological data remain missing, for instance whether the prevalence of knee OA evolves during a football career through the retirement years, whether knee OA is associated with knee injuries and surgeries, and whether knee OA leads to a lower level of functioning. Consequently, the present study focused on three research questions, namely: (i) what is the prevalence of knee OA among current and retired professional footballers? (ii) is severe knee injury or knee surgery associated with knee OA among current and retired professional footballers? (iii) what are the consequences of knee OA on physical knee function among current and retired professional footballers? The hypotheses related to these research questions were respectively: (i) the prevalence of knee OA among retired professional footballers was higher than among current professional footballers; (ii) knee OA was more prevalent among those professional footballers with more severe knee injuries or more knee surgeries; (iii) the level of physical knee function was lower among professional footballers with knee $\mathrm{OA}$ than among those without knee OA.

\section{Methods \\ Design}

An observational study based on a cross-sectional design by means of questionnaires was conducted, using the Strengthening the Reporting of Observational Studies in Epidemiology statement in order to guarantee the quality of reporting (Vandenbroucke et al. 2007). Ethical approval for the study was provided by the Ethical Committee of the Yokohama City Sports Medical Center (17.003; Yokohama, Japan) and the Medical Ethics Review Committee of the Academic Medical Center (W16_366\#16.431; Amsterdam, The Netherlands). The present study was conducted in accordance with the Declaration of Helsinki (2013).

\section{Participants}

The study population consisted of current and retired professional footballers recruited by the World Players' Union (FIFPro). Inclusion criteria were: (a) being a current or retired professional footballer; (b) being between 18 and 50 years; (c) being male; (d) being able to read and comprehend texts in English, French, or Spanish. In our study, the definition for a current or retired professional footballer was that he (i) trains (current) or has trained (retired) to improve football performances, (ii) competes (current) or has competed (retired) in the highest or second highest national league and (ii) has (current) or has had (retired) training and competition as major activity (way of living) or focus of personal interest, devoting several hours in all or most of the days for these activities, and exceeding the time allocated to other types of professional or leisure activities. Sample 
size calculation with regard to our first research question indicated that 196 participants in each study group were needed (power of $80 \%$, confidence interval of $95 \%$; absolute precision of 5\%) under the assumption of an anticipated population proportion of 20\% (Woodward 2014). Expecting a response rate of approximately 30\% (based on previous studies in professional sports), we intended to reach at least 1300 participants (650 in each study group) (Gouttebarge et al. 2016b; Schuring et al. 2016).

\section{Knee osteoarthritis and knee function (dependent variables)}

The presence of knee OA clinically diagnosed by a medical professional was examined through a single question ('Have you been diagnosed with knee osteoarthritis by a medical professional?'). For this question, the definition of knee OA (accordingly to the NICE criteria; adapted for age) was given to the participants as the damage of the knee joint's cartilage that leads to activity-related joint pain and either no morning joint-related stiffness or morning stiffness that lasts no longer than $30 \mathrm{~min}$ (National Clinical Guideline Centre 2014). To answer this question, participants were requested to consult either their medical record or their last team doctor.

The Knee injury and Osteoarthritis Outcome Score Physical Function Short Form (KOOS-PS) was used to assess the level of physical knee function (Lyman et al. 2016; Roos et al. 1998). The KOOS-PS has been validated in several study populations and languages including English, French and Spanish (Lyman et al. 2016; Ornetti et al. 2009; Roos et al. 1998; Vaquero et al. 2014. Based on the score on 7 items each measured on a 5-point scale (from 0 to 4 ) and subsequently converted, a total score ranging from 0 to 100 was calculated, where 0 represented total knee disability and 100 perfect knee function (Lyman et al. 2016). Reference values for physical knee function are available from the adult population but also from young athletic population and amateur footballers (Cameron et al. 2013; Frobell et al. 2008; Paradowski et al. 2006).

\section{Severe knee injury and related surgery (independent variable)}

History of severe knee injury and related surgery during a career as professional footballer was examined through a single question. In our study, a severe knee injury was defined as an injury that involved the knee joint, occurred during team activities (training or match), and led to either training or match absence for more than 28 days (Fuller et al. 2006). For this question, participants were recommended to consult either their medical record or their last team doctor.

\section{Procedures}

An electronic and/or paper anonymous questionnaire available in English, French and Spanish was compiled (LimeSurvey Professional), including the following descriptive variables (if applicable): age, body-height, body-weight, duration of professional football career, level of play, level of education, duration and nature of retirement, employment status. Information about the study was sent per email to potential participants by FIFPro, procedures being hidden from the principal researcher for privacy reasons. If interested in the study, all participants gave their informed consent and completed the electronic questionnaire. Participants were asked complete the questionnaire within 2 weeks, reminders being sent after 2 and 4 weeks. The responses to the questionnaires were coded and made anonymous for reasons of privacy and confidentiality. Once completed, the electronic questionnaires were saved automatically on a secured electronic server that only the principal researcher could access. Players participated voluntarily in the study and did not receive any reward for their participation.

\section{Statistical analyses}

The statistical software IBM SPSS 24.0 for Windows was used to perform all data analyses. Analyses were conducted separately for current and retired professional footballers. Descriptive analyses (mean, standard deviation (SD), frequency and range) were performed for all variables included in the study. Prevalence of knee OA was calculated (for the whole group and arbitrarily for three age categories per study group), using either the adjusted Wald method (sample size of 150 or less) or the Wald method (sample size of more than 150) for confidence intervals (Woodward 2014). Prevalence (expressed as percentage) was calculated as the proportion of the number of participants with knee OA relative to the total number of participants (Woodward 2014). Difference in the prevalence of knee OA between current and retired professional footballers was tested with the Chi-square test (Woodward 2014). In order to test the association of severe knee injury and knee surgery with knee OA, logistic regression analysis was performed (OA introduced as dichotomous dependent variable and injury/surgery as continuous independent variable), being adjusted for age and body mass index (BMI) as both have been identified as risk factors for OA (Felson 2004; Hunter et al. 2008). Considering that knee OA was shown to be common among professional footballers and that odds ratio tend to overestimate the calculated effect size, level of association was presented as risk ratio (RR) and 95\% confidence intervals (95\%CI) (Fernandes et al. 2017; Kuijt et al. 2012; Woodward 2014; Zhang and Yu 1998). Descriptive analyses related 
to level of physical knee function were conducted in the group of participants with and without knee OA. Comparisons between groups (participants with knee OA vs. participants without knee OA) were made using Mann-Whitney test for independent samples (Woodward 2014).

\section{Results}

\section{Participants}

From a total of 2500 footballers contacted (70\% current; $30 \%$ retired), 1360 gave their written informed consent and completed the questionnaire (overall response rate of 54\%): 964 current and 396 retired professional footballers. The mean age, height and weight of the group of current professional footballers was 26 years $(\mathrm{SD}=4)$, $180 \mathrm{~cm}(\mathrm{SD}=8)$ and $75 \mathrm{~kg}(\mathrm{SD}=9)$, respectively. Current players were playing professional football for 7 years on average, $67 \%$ playing at the highest club level in their country. The mean age, height and weight of the group of retired professional footballers was 36 years $(\mathrm{SD}=6), 181 \mathrm{~cm}(\mathrm{SD}=7)$ and $82 \mathrm{~kg}(\mathrm{SD}=9)$, respectively. Retired players had played professional football for 11 years on average $(81 \%$ at the highest club level in their country) and were retired for 5 years (30\% forced to retire). About $90 \%$ of these retired players were employed in a salaried position. All characteristics of the current and retired professional footballers (total and subgroups) are presented in Table 1.

\section{Knee osteoarthritis, severe injury and surgery}

Data on knee OA, severe knee injury and surgery among current and retired professional footballers is presented in
Table 2, while all prevalence rates of knee OA among current and retired professional footballers for the whole group and for three age categories per study group are presented in Fig. 1. Prevalence of knee OA was 13\% in the whole group of current professional footballers, being $8 \%$, $15 \%$ and $19 \%$ for the age groups $18-24$ years, $25-30$ years and $>30$ years, respectively. Around $59 \%$ of the current players had not incurred a severe knee injury during their career, $35 \%$ one or two severe knee injury, and $6 \%$ three or more. Around $73 \%$ of the current professional footballers had not undergone knee surgery during their career, 23\% one or two surgeries, and $4 \%$ three or more. Logistic regression analysis (Table 3) indicated that current professional footballers were nearly twice as likely to suffer from knee $\mathrm{OA}$ by every additional severe knee injury $(\mathrm{RR}=$ $1.74 ; 95 \% \mathrm{CI}=1.50-2.01 ; P<0.01)$ and by every additional surgery $(\mathrm{RR}=1.96 ; 95 \% \mathrm{CI}=1.66-2.29 ; \mathrm{P}<0.01)$.

Prevalence of knee OA was $28 \%$ in the whole group of retired professional footballers, being 19\%, 33\% and 34\% for the age groups $<35$ years, 35-40 years and $>40$ years, respectively. Around $42 \%$ of the retired players had not suffered from a severe knee injury during their career, $40 \%$ one or two severe knee injury, and $18 \%$ three or more. Around $51 \%$ of the retired professional footballers did not have had knee surgery during their career, $31 \%$ one or two surgeries, and $18 \%$ three or more. Logistic regression analysis (Table 3) indicated that retired professional footballers were nearly twice as likely to suffer from knee $\mathrm{OA}$ by every additional severe knee injury $(\mathrm{RR}=1.87 ; 95 \% \mathrm{CI}=1.61-2.13 ; \mathrm{P}<0.01)$ and by every additional surgery $(\mathrm{RR}=1.72 ; 95 \% \mathrm{CI}=1.50-1.95$; $\mathrm{P}<0.01$.

Table 1 Descriptive characteristics of current and retired professional footballers

\begin{tabular}{|c|c|c|c|c|c|c|}
\hline & \multicolumn{3}{|c|}{ Current professional footballers $(N=964)$} & \multicolumn{3}{|c|}{$\underline{\text { Retired professional footballers }(N=396)}$} \\
\hline & Total & No knee OA & Knee OA & Total & No knee OA & Knee OA \\
\hline Age (in years; mean $\pm S D$ ) & $26 \pm 4$ & $26 \pm 5$ & $28 \pm 4$ & $36 \pm 6$ & $36 \pm 6$ & $38 \pm 5$ \\
\hline Height (in cm; mean \pm SD) & $180 \pm 8$ & $180 \pm 8$ & $180 \pm 9$ & $181 \pm 7$ & $181 \pm 7$ & $181 \pm 6$ \\
\hline Weight (in kg; mean $\pm \mathrm{SD}$ ) & $75 \pm 9$ & $75 \pm 9$ & $75 \pm 10$ & $82 \pm 9$ & $82 \pm 9$ & $83 \pm 9$ \\
\hline Career duration (in years; mean $\pm S D$ ) & $7 \pm 4$ & $7 \pm 4$ & $8 \pm 5$ & $11 \pm 5$ & $11 \pm 5$ & $11 \pm 5$ \\
\hline Level of play (top league; \%) & 67 & 65 & 73 & 81 & 78 & 84 \\
\hline \multicolumn{7}{|l|}{ Educational level (\%) } \\
\hline No schooling completed & 2 & 2 & 5 & 1 & 0 & 2 \\
\hline Nursery/Elementary school & 3 & 4 & 2 & 2 & 3 & 1 \\
\hline High school & 45 & 45 & 40 & 28 & 30 & 28 \\
\hline Vocational/technical school & 16 & 15 & 19 & 8 & 7 & 7 \\
\hline College, university or equivalent & 34 & 34 & 34 & 61 & 60 & 62 \\
\hline \multicolumn{2}{|c|}{ Retirement duration (in years; mean \pm SD) } & & & $5 \pm 4$ & $5 \pm 4$ & $6 \pm 4$ \\
\hline \multicolumn{2}{|l|}{ Forced retirement (\%) } & & & 30 & 23 & 40 \\
\hline \multicolumn{2}{|l|}{ Employed (\%) } & & & 89 & 88 & 92 \\
\hline
\end{tabular}

$N$ number of participants, No knee $O A$, group without knee osteoarthritis, Knee OA group with knee osteoarthritis, SD, standard deviation, $\mathrm{cm}$, centimetres, $\mathrm{kg}$ kilograms, \% percentage 
Table 2 Knee osteoarthritis, severe knee injury and surgery, and physical knee function among current and retired professional footballers

\begin{tabular}{|c|c|c|}
\hline & Current professional footballers & Retired professional footballers \\
\hline Prevalence of knee OA $(\% ; 95 \% \mathrm{Cl})$ & $12.9(10.6-15.1)$ & $27.5(22.8-32.1)$ \\
\hline \multicolumn{3}{|l|}{ Severe knee injuries (mean; min-max) } \\
\hline Total & $0.7(0-10)$ & $1.4(0-10)$ \\
\hline No knee $O A$ & $0.6(0-10)$ & $0.890-10)$ \\
\hline Knee $O A$ & $1.7(0-10)$ & $3.2(0-10)$ \\
\hline \multicolumn{3}{|l|}{ Knee surgeries (mean; min-max) } \\
\hline Total & $0.5(0-7)$ & $1.2(0-10)$ \\
\hline No knee $O A$ & $0.3(0-6)$ & $0.7(0-10)$ \\
\hline Knee $O A$ & $1.4(0-7)$ & $2.8(0-10)$ \\
\hline \multicolumn{3}{|l|}{ KOOS-SP (mean \pm SD) } \\
\hline Total & $88 \pm 16$ & $82 \pm 19$ \\
\hline No knee $O A$ & $90 \pm 14$ & $88 \pm 16$ \\
\hline Knee $O A$ & $76 \pm 20$ & $64 \pm 16$ \\
\hline \multicolumn{3}{|l|}{ Reference value KOOS-SP (mean) } \\
\hline General population $^{a}$ & $87-92$ & $87-92$ \\
\hline Young athletic population ${ }^{b}$ & $86-99$ & $86-99$ \\
\hline Amateur footballers ${ }^{c}$ & $87-96$ & $87-96$ \\
\hline
\end{tabular}

No OA group without knee osteoarthritis, $O A$ group with knee osteoarthritis, SD standard deviation, ${ }^{\text {a }}$ Paradowski et al. $2006,{ }^{b}$ Cameron et al. 2013, ${ }^{\mathrm{c}}$ Frobell et al. 2008

Chi-square test indicated that the prevalence of knee OA among retired professional footballers was significantly higher than among current professional footballers $\left(\chi^{2}=37.63 ; \mathrm{df}=1 ; p<0.01\right)$. Prevalence rates of knee OA between age categories were significantly different $(\mathrm{p}<0.01)$ among both current and retired professional footballers, prevalence of knee OA being higher as players become older.

\section{Knee function}

Both current and retired professional footballers with knee OA reported a lower level of physical knee function than players without OA. The mean score on the KOOS-SP was 90 and 88 among current and retired professional footballers without knee OA, respectively, while the mean score on the KOOS-SP was 76 (Mann-Whitney test: $U=22,734 ; Z=-7.44 ; \mathrm{p}<0.01$ )

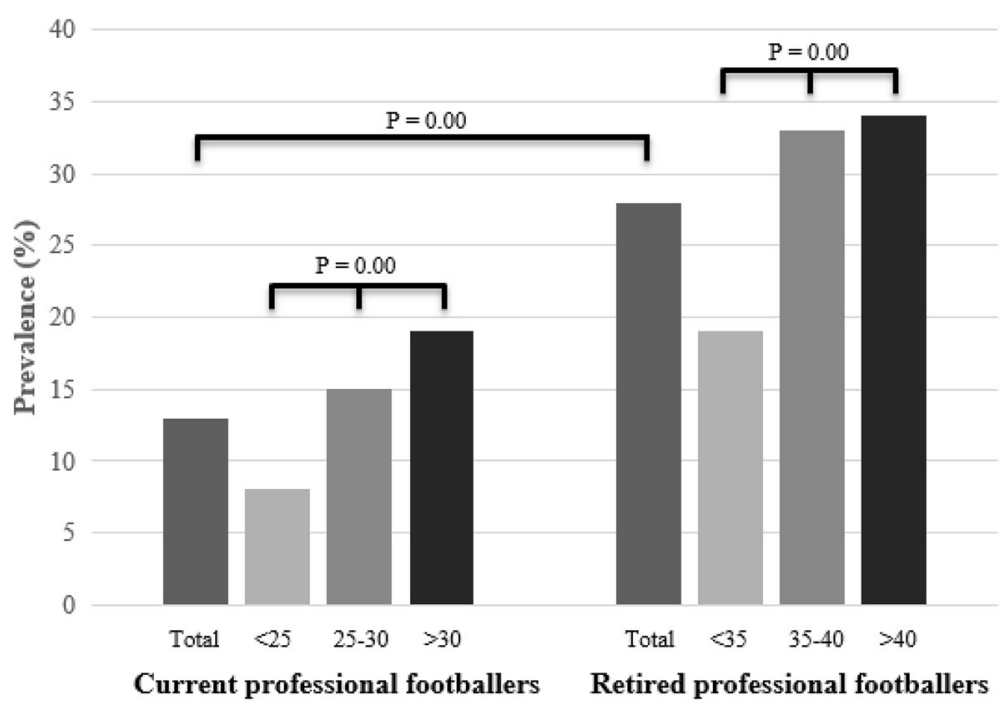

Fig. 1 Prevalence of knee osteoarthritis among current and professional footballers (total and three age categories) 
Table 3 Association (risk ratio and 95\% Cl) of severe knee injury and knee surgery with knee osteoarthritis among current and retired professional footballers

\begin{tabular}{llllll}
\hline & \multicolumn{2}{l}{ Current professional footballers } & & \multicolumn{2}{l}{ Retired professional footballers } \\
\cline { 2 - 3 } & Unadjusted & & Adjusted $^{a}$ & & \multicolumn{2}{l}{ Unadjusted } & Adjusted \\
\hline Number of severe knee injuries & $1.69(1.48-1.92)$ & $1.74(1.50-2.01)$ & & $1.62(1.45-1.80)$ & $1.87(1.61-2.13)$ \\
Number of knee surgeries & $1.94(1.68-2.23)$ & $1.96(1.66-2.29)$ & & $1.54(1.39-1.70)$ & $1.72(1.50-1.95)$ \\
\hline
\end{tabular}

${ }^{\mathrm{a}}$ Adjusted for age and body mass index (BMI)

and 64 (Mann-Whitney test: $\mathrm{U}=3834 ; \mathrm{Z}=-10.15 ; \mathrm{p}<$ 0.01 ) among current and retired professional footballers with knee OA. The KOOS-SP scores of the current and professional footballers without OA were similar to reference values from those from the general population, young athletic population and amateur footballers, but the KOOS-SP scores of the current and professional footballers with OA were lower that these reference values (Table 2).

\section{Discussion}

The principal findings of our study were that: (i) prevalence of knee OA was 13\% among current and 28\% among retired professional footballers, reaching up to $40 \%$ for the older age group; (ii) current and retired professional footballers were nearly twice as likely to suffer from knee OA by every additional severe knee injury and by every additional knee surgery incurred during a professional football career; and (iii) knee OA has negative consequences for the physical knee function of current and retired professional footballers, their physical knee function being lower than reference values from the general population, young athletic population and amateur footballers.

\section{Perspective of the findings}

Results from the scientific literature have shown that $\mathrm{OA}$ in the lower limbs, especially in the knees, is more prevalent among retired professional footballers than in the general population or employees from other occupational sectors (Kuijt et al. 2012; Gouttebarge et al. 2015; Salzmann et al. 2017). Recent literature overviews reported that the prevalence of knee OA among retired professional footballers ranged from $40 \%$ (clinical OA) to $80 \%$ (radiological OA), which is higher than the $18-34 \%$ from the general population or floor layers (Kuijt et al. 2012; Salzmann et al. 2017). A recent cross-sectional study conducted among 1207 retired professional footballers (mean age of 59 years) found that prevalence of radiological knee OA ranged from $28 \%$ to $80 \%$, which is higher than the prevalence found in a control group from the general population (10-50\%) (Fernandes et al. 2017). In this study, $40 \%$ to $65 \%$ of the retired professional footballers reported knee pain, whereas $20-30 \%$ of the control group reported knee pain (Fernandes et al. 2017). The authors need to mention the low response rate achieved in this study (25\%), which brings some questions with regard to selection bias and extern validity of the findings. Among retired elite athletes from other sport disciplines (endurance sports, track and field sports, power sports, team sports), prevalence of knee OA (clinical and arthroscopic diagnosis) was found to range between $16 \%$ and $55 \%$, with one study showing that $95 \%$ of athletes retired from various sports showed severe cartilage damage through arthroscopy (Gouttebarge et al. 2015).

In our study, we found that prevalence of knee OA was $28 \%$ among retired professional footballers (mean age of 36 years), reaching up to $40 \%$ for the older age group (40-50 years). Because of the difference in the mean age of the study populations, it remains difficult to make valid comparison with the aforementioned studies. However, it seems that our findings confirm the available scientific evidence on knee $\mathrm{OA}$ in retired professional footballers. Our study is the first one exploring the prevalence of knee OA among players being still active in professional football. With $13 \%$ on average, this prevalence of knee OA among current professional footballers was as expected significantly lower than among retired professional footballs. Also as expected, our findings show that prevalence of knee OA evolves over time during a football career through the retirement years. However, post-hoc regression analysis showed that the prevalence of knee OA among retired professional footballers was not significantly $(p=0.37)$ higher than among current professional footballers when adjusted for age. Prevalence of knee OA was associated with a lower level of physical knee function. This lower level of physical knee function is likely to lead to impairments in daily life, sport and/or work. Consequently, it remains essential to identify current and retired players having a predisposition for knee OA.

\section{Predisposition for knee OA}

The scientific literature has been rather conclusive about the sports-related contributing factors for knee OA. Especially knee injuries (e.g., meniscus tears, ACL deficiency or rupture) and surgeries seem to lead to a threefold increased risk for developing knee OA (Salzmann et al. 2017). In our study, we found that 
current and retired professional footballers were nearly twice as likely to suffer from knee OA by every additional severe knee injury and by every additional surgery. This evidence is essential in order to identify in early stage players predisposed for knee OA. For instance, a current professional footballer in his/her thirties and close to his/her retirement years should be advised to actively work on prevention of further injuries and (if possible) to avoid additional surgical treatment or at least should receive all information about his/her likelihood to develop knee OA in order to make an informed decision. The authors believe that this early identification will not prevent the occurrence of knee $\mathrm{OA}$ as injuries and surgeries can be seen as occupational hazards within the professional football industry. However, this early identification of predisposed players, especially at time of retirement, should facilitate the efforts directed towards the remission of knee OA among retiring/retired professional footballers and open possibilities for active preventive strategies.

\section{Methodological considerations}

Several methodological considerations within our study should be pointed out. Firstly, our cross-sectional study allowed us to explore the association between injuries/ surgeries and knee OA, but did not allow to establish a causal relationship. Therefore, a longitudinal study over a follow-up period of 25 to 30 years should be initiated, monitoring prospectively cumulative exposure of training/competition, injuries and surgeries in a large cohort of professional footballers far beyond their first retirement years. Secondly, as the recruitment procedures were blinded to the research team for privacy and confidentiality reasons, non-response analysis could not be conducted. However, with regard to the response rate achieved in our study (54\%) and the enrollment of 1360 current and retired professional footballers, we are confident that potential bias was avoided and that the external validity of our findings not jeopardized. Thirdly, one might argue that information about severe knee injuries and surgeries was partly self-reported. With regard to our experience collecting data in professional football, we know that players can generally remember quite precisely the number of severe knee injuries and surgeries they that led to at least 4 weeks without training or competition. However, we cannot categorically exclude that participants were unable to recall all the severe knee injuries during their entire career. Furthermore, the absence of data on the which knee was injured, operated or affected by OA might have biased our outcome estimates and thus remains a limitation in our study. Fourthly, one might assume that severe knee injuries and surgeries would have occurred prior the development of knee OA but because of our cross-sectional study design, such a time sequence is difficult to establish with certainty. This is a limitation in our study that might have led to some bias, jeopardising the causal interpretation of our findings. Lastly, clinical knee OA diagnosed by a medical professional was reported by the participants. The ideal measurement of knee OA would have been the clinical examination of all participants, which is barely feasible in large international research. Nevertheless, we strived to guarantee the validity of the data collected by stating clearly to all participants the definition of knee OA in our study and requesting them to consult either their medical record or last team doctor with regard to knee OA. In order to precisely appreciate the validity of the data collected, the concurrent validity of self-reported clinical knee OA with radiological knee OA might be explored.

\section{Implications towards the management of knee OA}

While its prevention seems utopic in professional football, the authors believe that the management of knee OA should be facilitated, especially among retiring/retired players. For current professional footballers during their career, the medical interdisciplinary team should especially focus on: (i) prevention of knee injuries; (ii) cautionary (negative) advice for the continuation of a football career for any predisposed player (that means who had suffered from injuries and/or surgeries) with knee joint deficiency; (iii) cautionary (negative) advice towards additional knee surgeries for any predisposed player, regardless of knee joint deficiency; (iv) raising the awareness of any player about the potential long-term consequences of knee injuries or surgeries and about the likelihood developing knee $\mathrm{OA}$, including the exponential worsening of the condition after retirement from football.

For retired players after their professional football career, the management of knee OA should aim to prevent the worsening of the condition, being especially directed towards pain alleviation, maintain functional status and minimize disability. However, retired professional footballers have mentioned that support measures directed towards their physical health were not available yet (Akturk et al. 2014). Consequently, in accordance to the needs of both current and retired professional footballers, the World Players' Union (FIFPro) has developed an After Career Consultation in order to empower their sustainable physical, mental and social health and quality of life, focusing among others on preventing the worsening of OA (Gouttebarge, Goedhart, Kerkhoffs: Empowering the health of retired professional footballers: the systematic development of an After Career Consultation and its feasibility, submitted). During this consultation, retired players receive information about OA, undergo a medical examination to identify potential problems 
related to the condition, and discuss (future) strategies to prevent its worsening. Strategies to prevent the worsening of OA rely especially on maintenance of optimal neuromuscular, i.e. proprioceptive functions, maintenance of sufficient range of motion, maintenance of good balance and joint stability, healthy lifestyle, i.e. weight control, pain management (coping) and general fitness through land-based and water-based exercises (Bennell et al. 2012; Kirkendall and Garrett 2012; McAlindon et al. 2014; Takeda et al. 2011; Zhang et al. 2010. As preliminary results on its pilot-implementation are positive, the implementation of the After Career Consultation should be prioritized by all stakeholders involved in professional football in order to empower the sustainable physical, mental and social health and quality of life of retired professional footballers.

\section{Conclusions}

The prevalence of knee OA was higher among retired than among current professional footballers and reached up to $40 \%$, leading to negative consequences for their physical knee function. Current and retired professional footballers were nearly twice as likely to suffer from knee OA by every additional severe knee injury and by every additional knee surgery incurred during their career. Management of knee OA should be prioritized among professional footballers, especially to prevent the worsening of the condition during their retirement years.

\section{Abbreviations}

ACL: Anterior Cruciate Ligament; FIFPro: World Players' Union; KOOS-PS: Knee injury and Osteoarthritis Outcome Score Physical Function Short Form; OA: Osteoarthritis; UEFA: Union of European Football Associations

\section{Acknowledgements}

The authors are grateful to all current and retired professional footballers who participated in the study.

\section{Availability of data and materials}

The data supporting the conclusions of this article is included within the article.

\section{Authors' contributions \\ VG was responsible for conceptualization of idea, preparation of study proposal, data collection, data analysis, interpretation of data and preparation of the manuscript. HA was responsible for the interpretation of data and preparation of the manuscript. GK was responsible for conceptualization of idea, preparation of study proposal, interpretation of data and critical review of the manuscript. All authors read and approved the final manuscript.}

\section{Ethics approval and consent to participate}

Ethical approval for the study was provided by the Ethical Committee of the Yokohama City Sports Medical Center (17.003; Yokohama, Japan) and the Medical Ethics Review Committee of the Academic Medical Center (W16_366\#16.431; Amsterdam, The Netherlands). Informed consent was given by all participants.

\section{Consent for publication}

All authors have consented for publication.

\section{Competing interests}

The authors declare that they have no competing interests.

\section{Author details}

'World Players' Union (FIFPro), Scorpius 161, 2132 LR Hoofddorp, The Netherlands. ${ }^{2}$ Department of Orthopaedic Surgery, Academic Medical Center, University of Amsterdam, Amsterdam Movement Sciences, Amsterdam, The Netherlands. ${ }^{3}$ Academic Center for Evidence based Sports medicine (ACES), Academic Medical Center, Amsterdam, The Netherlands. ${ }^{4}$ Amsterdam Collaboration on Health \& Safety in Sports (ACHSS), AMCNUmc IOC Research Center, Amsterdam, The Netherlands. ${ }^{5}$ Division of Exercise Science and Sports Medicine, University of Cape Town, Cape Town, South Africa. ${ }^{6}$ St. Marianna University School of Medicine, Kawasaki, Japan. ${ }^{7}$ Yokohama City Sports Medical Center, Yokohama, Japan.

Received: 27 February 2018 Accepted: 7 May 2018

Published online: 18 June 2018

\section{References}

Akturk A, Inklaar H, Gouttebarge V, Frings-Dresen MHW. Medical examinations in the Dutch professional football (soccer): a qualitative study. Int SportsMed J. 2014;15:343-51.

Bennell K, Hunter DJ, Hinman RS. Management of osteoarthritis of the knee. BMJ. 2012;345:e4934.

Cameron KL, Thompson BS, Peck KY, Owens BD, Marshall SW, Svoboda SJ. Normative values for the KOOS and WOMAC in a young athletic population: history of knee ligament injury is associated with lower scores. Am J Sports Med. 2013;41:582-9.

Drawer S, Fuller CW. Evaluating the level of injury in English professional football using a risk based assessment process. Br I Sports Med. 2002;36:446-51.

Felson DT. An update on the pathogenesis and epidemiology of osteoarthritis. Radiol Clin N Am. 2004:42:1-9.

Fernandes GS, Parekh SM, Moses J, Fuller C, Scammell B, Batt ME, et al. Prevalence of knee pain, radiographic osteoarthritis and arthroplasty in retired professional footballers compared with men in the general population: a cross-sectional study. Br J Sports Med. 2017; doi: 5. 10.1136/ bjsports-2017-097503

Frobell RB, Svensson E, Göthrick M, Roos EM. Self-reported activity level and knee function in amateur football players: the influence of age, gender, history of knee injury and level of competition. Knee Surg Sports Traumatol Arthrosc. 2008;16:713-9.

Fuller CW, Ekstrand J, Junge A, Andersen TE, Bahr R, Dvorak J, et al. Consensus statement on injury definitions and data collection procedures in studies of football (soccer) injuries. Br J Sports Med. 2006;40:193-201.

Gouttebarge V, Aoki H, Ekstrand J, Verhagen EA, Kerkhoffs GM. Are severe musculoskeletal injuries associated with symptoms of common mental disorders among male European professional footballers? Knee Surg Sports Traumatol Arthrosc. 2016b;24:3934-42.

Gouttebarge V, Hughes Schwab BA, Vivian A, Kerkhoffs G. Injuries, matches missed and the influence of minimum medical standards in the a-league professional football: A 5-year prospective study. Asian J Sports Med. 2016a;7: e31385.

Gouttebarge V, Inklaar H, Backx F, Kerkhoffs G. Prevalence of osteoarthritis in former elite athletes: a systematic overview of the recent literature. Rheumatol Int. 2015:35:405-18.

Gouttebarge V, Inklaar H, Frings-Dresen MH. Risk and consequences of osteoarthritis after a professional football career: a systematic review of the recent literature. J Sports Med Phys Fitness. 2014;54:494-504.

Hermans J, Koopmanschap MA, SMA B-Z, van Linge JH, Verhaar JA, Reijman M, et al. Productivity costs and medical costs among working patients with knee osteoarthritis. Arthritis Care Res. 2012;64:853-61.

Hunter DJ, McDougall JJ, Keefe FJ. The symptoms of OA and the genesis of pain. Rheum Dis Clin N Am. 2008;34:623-43.

Kirkendall DT, Garrett WE. Management of the retired athlete with osteoarthritis of the knee. Cartilage. 2012;3:69S-76S.

Kuijt K, Inklaar H, Gouttebarge V, Frings-Dresen M. Knee and ankle osteoarthritis in former elite soccer players: a systematic review of the recent literature. J Sci Med Sport. 2012;15:480-7.

Lohkamp M, Kromer TO, Schmitt H. Osteoarthritis and joint replacements of the lower limb and spine in ex-professional soccer players: a systematic review. Scand J Med Sci Sports. 2017;27:1038-49.

Lohmander LS, Englund PM, Dahl LL, Roos EM. The long-term consequence of anterior cruciate ligament and meniscus injuries. Am J Sports Med. 2007;35: 1756-69. 
Lyman S, Lee YY, Franklin PD, Li W, Cross MB, Padgett DE. Validation of the KOOS, JR: a short-form knee arthroplasty outcomes survey. Clin Orthop Relat Res. 2016;474:1461-71.

McAlindon TE, Bannuru RR, Sullivan MC, Arden NK, Berenbaum F, Bierma-Zeinstra $S M$, et al. OARSI guidelines for the non-surgical management of knee osteoarthritis. Osteoarthr Cartil. 2014;22:363-88.

McWilliams DF, Leeb BF, Muthuri SG, Doherty M, Zhang W. Occupational risk factors for osteoarthritis: a meta-analysis. Osteoarthr Cartil. 2011;19:829-39.

National Clinical Guideline Centre (UK). Osteoarthritis: care and Management in Adults. London: National Institute for Health and Care Excellence (UK); 2014

Ornetti P, Perruccio AV, Roos EM, Lohmander LS, Davis AM, Maillefert JF. Psychometric properties of the French translation of the reduced KOOS and HOOS (KOOS-PS and HOOS-PS). Osteoarthr Cartil. 2009;17:1604-8.

Paradowski PT, Bergman S, Sunden-Lundius A, Lohmander LS, Roos EM. Knee complaints vary with age and gender in the adult population. Populationbased reference data for the knee injury and osteoarthritis outcome score (KOOS). BMC Musculoskelet Disord. 2006;7:38.

Roos EM, Roos HP, Lohmander LS, Ekdahl C, Beynnon BD. Knee injury and osteoarthritis outcome score (KOOS) - development of a self-administered outcome measure. J Orthop Sports Phys Ther. 1998;78:88-96.

Salzmann GM, Preiss S, Zenobi-Wong M, Harder LP, Maier D, Dvorák J. Osteoarthritis in football. Cartilage. 2017:8:162-72.

Schuring N, Aoki H, Gray J, Kerkhoffs G, Lambert M, Gouttebarge V. Osteoarthritis is associated with symptoms of common mental disorders among former elite athletes. Knee Surg Sports Traumatol Arthrosc. 2016;25:3179-85.

Takeda H, Nakagawa T, Nakamura K, Engebretsen L. Prevention and management of knee osteoarthritis and knee cartilage injury in sports. Br J Sports Med. 2011:45:304-9.

Vandenbroucke JP, von Elm E, Altman DG, Gotzsche PC, Mulrow CD, Pocock SJ, et al. Strengthening the reporting of observational studies in epidemiology (STROBE): explanation and elaboration. Epidemiology. 2007;18:805-35.

Vaquero J, Longo UG, Forriol F, Martinelli N, Vethencourt R, Denaro V. Reliability, validity and responsiveness of the Spanish version of the knee injury and osteoarthritis outcome score (KOOS) in patients with chondral lesion of the knee. Knee Surg Sports Traumatol Arthrosc. 2014;22:104-8.

Vrezas IE. Case-control study of knee osteoarthritis and lifestyle factors considering their interaction with physical workload. Int Arch Occup Environ Health. 2010;83:291-300

Walden M, Hagglund M, Magnusson H, Ekstrand J. ACL injuries in men's professional football: a 15-year prospective study on time trends and returnto-play rates reveals only $65 \%$ of players still play at the top level 3 years after ACL rupture. Br J Sports Med. 2016;50:744-50.

Woodward M. Epidemiology : study design and data analysis. Boca Raton: CRC Press; 2014

Zhang J, Yu KF. What's the relative risk? A method of correcting the odds ratio in cohort studies of common outcomes. JAMA. 1998;280:1690-1.

Zhang W, Nuki G, Moskowitz RW, Abramson S, Altman RD, Arden NK, et al. OARSI recommendations for the management of hip and knee osteoarthritis: part III: changes in evidence following systematic cumulative update of research published through January 2009. Osteoarthr Cartil. 2010;18:476-99.

\section{Submit your manuscript to a SpringerOpen ${ }^{\circ}$ journal and benefit from:}

- Convenient online submission

- Rigorous peer review

- Open access: articles freely available online

- High visibility within the field

- Retaining the copyright to your article

Submit your next manuscript at $>$ springeropen.com 